\title{
Comparing three conventional penaeid-trawl otter boards and the new batwing design
}

Matthew J. McHugh ${ }^{\mathrm{a},{ }^{*}}$, Matt K. Broadhurst ${ }^{\mathrm{a}, \mathrm{b}}$, David J. Sterling ${ }^{\mathrm{c}}$, Russell B. Millar ${ }^{\mathrm{d}}$

$5 \quad$ a Marine and Estuarine Ecology Unit, School Of Biological Sciences (Goddard Building), University of Queensland Brisbane, QLD 4072, Australia

${ }^{\mathrm{b}}$ NSW Department of Primary Industries, Fisheries Conservation Technology Unit, PO Box 4321, Coffs Harbour, NSW 2450, Australia

${ }^{\mathrm{c}}$ Sterling Trawl Gear Services, 187 Ernest St, Manly, QLD 4179, Australia

10

${ }^{\mathrm{d}}$ Department of Statistics, The University of Auckland, Private Bag 92019, Auckland, New Zealand

*Corresponding author. tel: +61 26648 3915; fax: +61 266516580

E-mail address: matthew.mchugh@uq.net.au (M. J. McHugh)

15

\section{Abstract}

Three experiments were conducted to compare the engineering and catching performances of a hydrodynamic otter board termed the 'batwing' (comprising a sled-and-sail assembly, configured to operate at $20^{\circ}$ angle of attack-AOA and with minimal bottom contact) against three conventional

20 designs (termed the 'flat-rectangular'; 'kilfoil' and 'cambered' otter boards) with AOAs between $\sim 30$ and $40^{\circ}$. Experiments involved paired penaeid trawls $(7.35-\mathrm{m}$ headlines). The first experiment compared the batwing otter boards against all other designs (using 41-mm mesh trawls). In experiment 2 , the batwing was tested against the flat-rectangular design (with 32-mm mesh trawls). In experiment 3 , the batwing and flat-rectangular otter boards were towed without trawls to facilitate estimates of their partitioned drag. Overall, compared to the conventional otter boards, the batwings had up to $~ 86$ and $18 \%$ less bottom contact and drag, respectively. Among the conventional otter boards, the trawls spread by the cambered design caught up to 13\% more school prawns Metapenaeus macleayi; attributed to their greater solid profile. No significant differences were detected among catches of fish in the trawls spread by the various otter boards. The results reaffirm that because otter boards contribute towards a large proportion of total system drag (estimated here at up to $\sim 56 \%$ ), their appropriate configuration is essential to maximise the fuel efficiency of penaeid-trawl systems.

Keywords: drag, fuel reduction, habitat impacts, otter-board design, penaeids, 
Penaeids are targeted throughout the world's tropical and temperate regions; mostly using small fishing vessels $(<25 \mathrm{~m})$ towing multi-net trawl systems that are laterally spread by paired hydro vanes, called 'otter boards' (Kelleher, 2005; Gillett, 2008). While there is considerable variety among otterboard designs, all encompass a substantial proportion of the entire trawling system weight to ensure sufficient seabed contact, and are orientated at an angle to the tow direction (termed the angle of attack-AOA). The water moving over otter boards creates hydrodynamic forces that horizontally open penaeid trawls to spread ratios (SR) typically 0.6 to 0.8 of their total headline length. The drag component of such hydrodynamic forces has been hypothesised to account for up to $30 \%$ of the totalsystem drag (Sterling, 2000).

At a broad level, the most common otter boards are simple flat, rectangular designs-although more hydrodynamically complex cambered variations are also popular (Seafish et al., 1993). Irrespective of design subtleties, the majority of otter boards are rigged to have AOAs between 30 and $40^{\circ}$ (Seafish et al., 1993; Sterling, 2000). Operating conventional otter boards at such high AOAs helps to maintain their stability, which keeps the other trawl components at optimal efficiency (Patterson

50 and Watts, 1985). Even slight reductions in AOA below this range can result in operational issues, manifesting as reduced stability and possibly lost effective fishing time (Patterson and Watts, 1985; Seafish et al., 1993). In an attempt to overcome such issues, a more recent prototype termed the 'batwing' otter board was developed by Sterling and Eayrs (2010) to remain at a constant $20^{\circ} \mathrm{AOA}$, and with robust stability achieved through its unique rigging strategy (see Methods).

55 Although not extensively quantified (but see Patterson and Watts, 1985; 1986), compared to conventional designs, otter boards such as the batwing that have low AOAs should have relatively lower drag for the same spreading force and therefore require less fuel to tow. Calculating the extent of any such fuel reductions is complex. It is well established that the fuel consumed during trawling is proportional to the thrust applied by the trawler, if propeller efficiency remains constant (Prado, 1990).

60 However, the assumption of a proportional relationship between drag reductions and fuel savings remains approximate because many factors affect efficiency, including propeller loading.

Globally, it is becoming imperative to reduce fuel usage in many fisheries including demersal trawling, which has some of the greatest fuel-to-catch ratios, with fuel accounting for $30 \%$ of a trawl operator's total costs in developed countries (Suuronen et al., 2012). In fact, in Australia, trawlers use

65 at least $55 \%$ of their fuel while trawling (with the rest used during travelling between trawl grounds and operating electrical equipment), and are operating close to their profitability threshold (Thomas et al., 2010; Wakeford, 2010).

Beyond drag/fuel savings, a potential concomitant benefit of lowering otter-board AOA is reduced benthic contact for any given length (i.e. $\sim 1.5 \%$ for each degree the AOA is lowered), and subsequently fewer associated impacts. For example, an otter board $\sim 1 \mathrm{~m}$ long deployed at $40^{\circ} \mathrm{AOA}$ will impact the bottom for $\sim 64 \mathrm{~cm}$, while at $20^{\circ}$ its contact will be reduced to $\sim 34 \mathrm{~cm}$. Even slight reductions in impacts are potentially beneficial, considering that otter boards leave the most discernible track marks from trawl configurations (Caddy, 1973; Kaiser et al., 2002). However, from a catching perspective, one concern with minimising otter-board bottom contact is that a lower AOA

75 could reduce substrate disturbance and negatively affect catches because penaeids mostly reside in the substratum (Broadhurst et al., 2012; 2013a; McHugh et al., 2014). Further, otter boards are known to herd fish (Wardle, 1989), either through visual or tactile stimuli, and so even subtle variation in their design and AOA might influence species selection by the trawl.

Despite the above, there have been very few formal studies of the effects of otter boards on the engineering (e.g. AOA and spreading force) and catching performances of penaeid trawls (but see Broadhurst et al., 2012; 2013b). The main aim of this study was to address this shortfall by quantifying the catches and fuel efficiency (measured as least drag) associated with three conventional otter-board designs and the batwing (with its relatively less bottom contact) in one Australian fishery targeting school prawns, Metapenaeus macleayi. A secondary aim was to use an approach involving removing the trawls 85 and just towing the otter boards (separated by wire stays) to quantify their contribution towards total system drag for the tested trawls, so the benefits of future refinements to otter-board design and their AOAs can be established. 


\section{Methods}

Three experiments were completed in the Clarence River, New South Wales, Australia, during May

2013 using a local penaeid trawler (10 $\mathrm{m}$ and 89-kw) fishing in $\sim 4-18 \mathrm{~m}$ water-depth across mud and sand substratum. The trawler had 8-mm diameter ( $\varnothing$ ) stainless warps and $40-\mathrm{m}$ bridles $(6-\mathrm{mm} \varnothing$ stainless wire) on a double-drum, hydraulic split winch. The trawler was also equipped with: a fuel monitor (Floscan series 9000); global positioning system (GPS; Lowrance); hull-mounted sum log (EchoPilot, Bronze Log+), warp-attachable load cells and associated data logger (Amalgamated

95 Instrument Company; model nos PA6139 and TP4); and a portable acoustic, trawl-monitoring system with paired wing-end distance sensors (Notus Trawlmaster System; Model no. TM800ET; see Broadhurst et al., 2013a for details). All monitoring equipment was calibrated prior to starting the experiments.

\section{$100 \quad 2.1 . \quad$ Trawls and otter boards tested}

Four trawls were constructed - two identical replicates of two similar designs (Fig. 1). The first two trawls (termed A and B) were conventionally mandated designs for the fishery, and comprised a mean stretched mesh opening $(\mathrm{SMO}) \pm \mathrm{SE}$ of $41.43 \pm 0.11 \mathrm{~mm}(\mathrm{n}=20$ meshes in each trawl $)$ and 1.2-mm $\varnothing$ twine, with a side taper of 1N3B and were used in experiment 1 (Fig. 1). Owing to the small sizes of 105 prawns encountered (see Results), the third and fourth trawls (labelled $\mathrm{C}$ and D) used in experiment 2 were made from smaller $31.61 \pm 0.08 \mathrm{~mm} \mathrm{SMO}(\mathrm{n}=20$ meshes in each trawl $)$ and $0.8 \mathrm{~mm} \emptyset$ twine, and with a side taper of 1N5B (Fig. 1). All four trawls were rigged with identical Nordmøre-grids and square-mesh codends made from $27.37 \pm 0.10$-mm SMO $(n=20$ meshes in each trawl) polyamide mesh hung on the bar and had 2.89-m sweeps (6-mm Ø wire) attached at their wing ends, terminating in snap clips to facilitate attachment to the otter boards.

Four otter-board pairs were tested, all with $100 \mathrm{~mm}$ base plates (Fig. 2). The first otter board represented a standard design used nationally and internationally, and comprised a mild-steel frame with marine-grade plywood inserts and was termed the 'flat-rectangular' $(52.5 \mathrm{~kg}, 1.39 \times 0.61 \mathrm{~m}$, solid area of $0.77 \mathrm{~m}^{2}$; Fig. 2a). The second design ('kilfoil') was constructed entirely from galvanized 115 mild steel and had three $270 \mathrm{~mm}$-wide cambered vertical foils in a rectangular frame $(63.0 \mathrm{~kg}, 1.25 \times$ $0.63 \mathrm{~m}$, solid area of $0.58 \mathrm{~m}^{2}$; Fig. 2b), while the third ('cambered') had a single, cambered foil over its entire length and was made from stainless-steel plate $\left(53.0 \mathrm{~kg}, 1.08 \times 0.73 \mathrm{~m}, 0.79 \mathrm{~m}^{2} ; \mathrm{Fig} .2 \mathrm{c}\right)$.

The fourth design was the batwing and comprised a main sled made from mild and stainless steel, and a polyurethane (PU) sail set on a stainless-steel boom and mast $\left(60.7 \mathrm{~kg}, 1.12 \times 1.23 \mathrm{~m}, 0.74 \mathrm{~m}^{2}\right)$ configured to remain at a $20^{\circ}$ AOA (Fig. 2d). The batwing foil was designed to act like an independent kite with a single longitudinal connection to the trawl system via a heavy main sled made from a combination of mild and stainless steel (Fig. 2d). The batwing was configured so that the heavy sled baseplate was aligned to the tow direction, while the sail had a stable AOA and rode on a polyurethane flap designed to pass lightly over the seabed on a layer of pressurised water (similar in concept to the skirt on a hovercraft).

To ensure the same trawl wing-end height during fishing, vertical upper sweep attachment bars were welded to the tops of the flat-rectangular and kilfoil designs to match the heights of the cambered and batwing otter boards (Fig. 2). All otter boards were rigged at their industry-standard AOAs, and to achieve the same trawl wing-end spreads (see Results).

\subsection{Experiment 1-four pairs of otter boards with trawls}

In the first experiment, the four otter boards were tested against each other in paired comparisons. On each fishing day, one of the six possible otter-board combinations was attached to each side of the vessel. The 41-mm trawls (A and B) and sweeps were clipped to the otter boards, while the Notus paired sensors

135 were attached to the trawl wing ends. After two replicate deployments, the trawl-monitoring equipment (Notus sensors and load cells) were swapped from side-to-side, but the trawls remained. After four replicate deployments, both the trawls and the trawl-monitoring equipment were swapped from side-toside. After six deployments, just the trawl-monitoring equipment was swapped again. In total, each of the four otter-board pairs were deployed across three alternate replicate days, with eight replicate 30-min deployments for each treatment on each day (providing a total of 24 deployments). 


\subsection{Experiment 2-two pairs of otter boards with trawls}

To obtain more data over a broader range of conditions (and especially longer tow durations more representative of conventional operations), just the flat-rectangular and batwing otter boards were compared. On each of four days, pairs of the two otter boards were alternately attached to each side of the vessel, and clipped to the sweeps attached to the 31-mm trawls. The smaller-mesh trawls were used to remove the possibility that confounding distortion of the trawls (particularly in the side panels) caused by the strain-equalizing mechanism of the batwing otter boards allowed small school prawns to escape (see Results and Discussion). The trawl monitoring equipment was randomly allocated to one side of the vessel on each day. Five 50-min deployments were completed on each day (i.e. a total of 20 deployments for each otter board), swapping the trawls from side-to-side after the third deployment.

\subsection{Experiment 3-two pairs of otter boards without trawls}

In experiment 3 , the flat-rectangular and batwing otter boards were again tested against each other as for experiment 2, but with the trawls removed to obtain drag estimates for the otter boards only. To limit

155 separation of the otter boards and fix the AOA, two lengths of 3-m stainless steel wire (6-mm Ø) were secured between the upper and lower net attachment points on each otter board pair and a third wire (3.5 m) was connected between each otter-board pair at the warp connection points (Fig. 3). The trawl monitoring equipment was alternately allocated to one side of the vessel on each day (with the Notus paired sensors secured to the outside posterior surface of each otter board; Fig. 3) and between 8 and 12 replicate deployments completed over four days (total $n=40$ ).

\subsection{Data collected and statistical analyses}

In all three experiments, the technical data collected describing the operational procedures during each deployment included the: (i) drag (kgf) of each gear configuration; (ii) total distance the gears were towed

165 (otter boards on and off the bottom - obtained from the plotter and trawl-monitoring system); (iii) speed over the ground (SOG) and through the water (STW; both in $\mathrm{ms}^{-1}$ ), (iv) water depth (m), (v) distance of the gear configurations behind the vessel, and (vi) wing-end (experiments 1 and 2) or otter-board (experiment 3 ) spreads (m). All electronic data were recorded at 60-s intervals. For experiments 1 and 2, otter-board AOA was estimated using the otter-board orientation model of Sterling (2000) with inputs of

170 wing-end spread (for each deployment) and used to calculate otter-board span (contact) on the substrate (by multiplying the otter-board length by the sine of the AOA) and ultimately, the effective total bottom contact (average wing-end spread + otter-board lateral base-plate contact).

At the end of each deployment in experiments 1 and 2, all catches were separated by codend, with the total weights of school prawns and bycatch collected along with the numbers of each bycatch species.

175 Total lengths (TL to the nearest $0.5 \mathrm{~mm}$ ) of the most abundant teleosts were also collected. A random sample of $\sim 500 \mathrm{~g}$ of school prawns was collected and a subsample ( 100) measured (carapace length$\mathrm{CL}$ in $\mathrm{mm}$ ) in the laboratory. These data were used to estimate the total numbers caught and mean CL during each deployment.

The technical and biological data were separately analysed within experiments using linear mixed 180 models (LMMs), with some standardised prior to analyses. Numbers and weights were analysed as log-transformed data, after being standardised to per ha trawled calculated using the foot-rope contact (average wing-end spread $\times$ distance trawled) and, additionally where these were significant for school prawns, the effective total-system contact ((i.e. wing-end spread + span of otter-board contact) $x$ the distance trawled) for fishing. The latter was done to test the hypothesis that otter-board contact

185 span explained some of the variability in school prawn catches (see Results), and did not include the batwing sleds, because these were outside the effective herding path of the trawl (Broadhurst et al., 2012). All other data, including the mean CL of school prawns per deployment, drag, wing-end spread, SOG, STW and distance trawled were analysed in their raw form.

All models included 'otter-board pair' as a fixed effect while, where appropriate (depending on the 190 experiment), the random effects included 'trawls', 'trawl sides', 'otter-board sides' and 'days' and the interaction between 'deployments' and days. For the LMMs assessing drag and spread, additional random terms involved load cells and the paired Notus sensors, respectively while additional covariates included SOG, 'current' (calculated as the speed of the water in the direction of travel and defined as SOG-STW), distance aft of the trawl configuration from the vessel and fishing depth. All

195 models were fitted using the lmer function from the lme4 package in R 2.15.3 (The R Project for 
Statistical Computing; http://www.r-project.org/) and the significance of trawl design was determined using a likelihood ratio test (LRT). The LRT was used to compare model log-likelihoods and test whether any differences were statistically significant (Rice, 2006). In experiment 1 , where the levels of otter-board pair exceeded two, significant differences were explored using the BenjaminiHochberg-Yekutieli procedure to control the false discovery rate (FDR; Benjamini and Yekutieli, 2001). The FDR is the expected proportion of false positive discoveries between all of the rejected hypotheses.

Relevant back-transformed predicted means from the LMMs were used to calculate relative fuel consumptions associated with towing the trawls and otter boards in experiments 1 and 2. Specifically,

205 assuming that for any given towing speed, the concomitant fuel usage was proportional to the drag, it is possible to determine relative fuel consumption rate $\left(\mathrm{L} \mathrm{h}^{-1}\right)$ between each side using the predicted mean drags as determined by the repeated load-cell measurements. Fuel consumption was standardised to per ha trawled (i.e. intensity) and per kg of school prawns caught for each otter-board configuration by comparing the predicted fuel consumption rate with predicted mean wing-end spread 210 (the rate at which area was being swept for a given trawl speed), and the predicted absolute mean school prawn catches (derived by fitting the same model above to the unstandardized log-transformed data) from the respective LMMs.

\section{Results}

215 School prawns comprised 99\% of the total catches in experiments 1 and 2 (Table 1). The minimal bycatch included 25 species, but was dominated by forktail catfish (Arius graeffei; $8.0-13.5 \mathrm{~cm} \mathrm{TL}$ ), southern herring (Herklotsichthys castelnaui; 7.0-16.0 cm TL) and mulloway (Argyrosomus japonicas; 4.5-20.5 cm TL) in experiment 1 (80\% of the total catch) and yellowfin bream (Acanthopagrus australis; $6.5-23.5 \mathrm{~cm} \mathrm{TL})$ and southern herring (7.0-15.5 cm TL) in experiment 2 220 (64\%) (Table 1).

\subsection{Experiment 1-four pairs of otter boards with trawls}

The four otter-board and trawl configurations were towed at (mean \pm SE) SOG of $1.24 \pm 0.01 \mathrm{~ms}^{-1}$ and STWs of $1.43 \pm 0.08 \mathrm{~ms}^{-1}$. There was no significant difference in the wing-end spreads of the 225 trawls rigged among otter-board pairs, nor distance trawled (LMM, $p>0.05$; Tables 2 and 3), but otter-board AOAs, total bottom contact and drag were all significantly different (LMMs, $p<0.01$; Tables 2 and 3). Specifically, while the batwing maintained a $20^{\circ}$ AOA, the kilfoil $\left(30.58 \pm 0.04^{\circ}\right)$, flat-rectangular $\left(32.83 \pm 0.04^{\circ}\right)$ and cambered $\left(38.62 \pm 0.04^{\circ}\right)$ designs were spread at significantly (and incrementally) greater AOAs (FDR, $p<0.05$; Tables 2 and 3). However, the AOAs did not 230 significantly affect the total bottom contact (because the different otter-board lengths offset any relative reductions) among the conventional configurations (FDR, $p>0.05$; Tables 2 and 3), but all three had significantly greater total bottom contacts than the batwing configuration (up to 1.24 times more; FDR, $p<0.05$; Table 3). For individual otter boards (from the four designs), a combination of their AOA and length altered (by up to $66 \%$ ) their projected surface area to between $\sim 0.25$ and $\sim 0.48$

\section{$235 \mathrm{~m}^{2}$}

The LMM for drag included the fixed effects of otter-board pair, SOG and current, with the former two being significant $(p<0.05)$. To facilitate presentation, the predicated mean drags were calculated at the centred value of SOG (i.e. drag at average SOGs) and for zero current (Table 3). Compared to all three conventional systems, the batwing configuration had significantly less drag (predicted mean reduced by between 14.00 and $18.34 \%$ ). Further, compared to the kilfoil and cambered otter-board configurations (which had the same drag; FDR, $p>0.05$; Table 3), there was less drag associated with the flat-rectangular configuration (by 5\%; FDR, $p<0.05$; Table 3 ). The fuel rate varied between $\sim 5.00$ and $\sim 6.13 \mathrm{~L} \mathrm{~h}^{-1}$ while fuel intensity was between $\sim 2.20$ and $\sim 2.68 \mathrm{~L} \mathrm{ha}^{-1}$, with the batwing otter boards requiring the least fuel to tow (Table 3).

245 For the biological variables, significant differences were limited to school prawn catches, with the most consistent difference being that the batwing configuration retained significantly fewer individuals per ha of footrope contact (by both weight and number) than the conventional configurations (LMM, $p<0.05$, Table 2, Fig. $4 \mathrm{a}$ and $\mathrm{b}$ ). Standardizing catches to per ha of totalsystem contact (to incorporate the otter-board span on the bottom) eliminated some of the significant 250 differences among the conventional and batwing configurations, but not all (Fig. 4a and b). In 
particular, the cambered otter-board configuration retained significantly more school prawns by weight (by between 11 and 33\%) than the other designs, and also at a significantly smaller mean size $(15.22 \pm 0.11 \mathrm{~mm} \mathrm{CL})$ than the batwing configuration $(15.52 \pm 0.11 \mathrm{~mm} \mathrm{CL})(\mathrm{FDR}, p<0.05$; Fig. 4a). Although not significant, the cambered otter-board configuration also caught a smaller mean CL 255 of school prawns than the kilfoil $(15.27 \pm 0.11 \mathrm{~mm} \mathrm{CL})$ and flat-rectangular $(15.34 \pm 0.11 \mathrm{~mm} \mathrm{CL})$ $(\mathrm{FDR}, p>0.05)$. No significant differences were detected for catches of fish (LMM, $p>0.05$; Table 2, Fig. $4 \mathrm{c}-\mathrm{g}$ ).

\subsection{Experiment 2-two pairs of otter boards with trawls}

260 The flat-rectangular and batwing otter-board configurations were towed at mean \pm SE SOGs and STWs of $1.29 \pm 0.01$ and $1.28 \pm 0.01 \mathrm{~ms}^{-1}$. There was no significant difference in the wing-end spread of the 31-mm mesh trawls rigged between otter-board pairs, nor the distance trawled (LMM, $p$ $>0.05$; Tables 2 and 3), however like for experiment 1, the AOA, total-bottom contact and drag were all significantly different (LMMs, $p<0.001$; Tables 2 and 3). The differences between otter-board

265 pairs for AOA, total bottom contact and projected surface area followed those for experiment 1 (Tables 2 and 3). For drag, the parsimonious LMM included a significant interaction between gear and SOG and a significant main effect of current $(p<0.01)$. The predicated mean drags for the two configurations are presented at the centred value of SOG (i.e. drag at average SOGs) and for zero current; under which criteria the batwing configuration had $\sim 15 \%$ less drag than the flat-rectangular configuration (Table 3). The fuel rate equated to $\sim 5.28$ and $\sim 6.21 \mathrm{~L} \mathrm{~h}^{-1}$ while fuel intensity was $\sim 2.00$ and $\sim 2.33 \mathrm{~L} \mathrm{ha}^{-1}$ for the batwing and flat-rectangular otter boards, respectively (Table 3 ).

In terms of catches per ha trawled of foot-rope contact, no significant differences were detected between otter-board configurations for any of the variables, although the predicted mean weights and numbers of school prawns were 5.07 and $7.67 \%$ lower for the batwing configuration (LMM, $p>0.05$,

275 Table 2 and 4). Further, although there were few data $(\mathrm{n}=104)$, the LRT $p$-value for yellowfin bream catches was 0.09 , with a corresponding 1.4 times mean increase in the numbers retained in the batwing configuration (Table 2 and 4).

\subsection{Experiment 3-two otter boards without trawls}

280 Substituting a trawl with wire stays between the paired flat-rectangular and batwing otter boards presented few logistical problems, with both configurations towed at mean \pm SE SOGs and STWs of $1.31 \pm 0.01$ and $1.69 \pm 0.06 \mathrm{~ms}^{-1}$. Compared to the flat-rectangular otter-board pair, the batwing pair were spread significantly wider (11\% difference in predicted means) and at a lower AOA (20 $\pm 00 \mathrm{vs}$ $32.59 \pm 2.13^{\circ}$; LMM, $p<0.01$; Tables 2 and 3). The parsimonious LMM for drag comprised a 285 significant interaction between otter-board configuration and SOG, and a main effect of current $(p<$ 0.01; Table 3). At average SOG and for zero current, the predicated mean drag of the batwing pair was $116.75 \pm 3.77 \mathrm{~kg}$, or $26 \%$ less than that for the flat-rectangular otter board $(158.65 \pm 3.79 \mathrm{~kg}$; Table 3).

\section{4. Discussion}

Compared to the conventional otter boards, the batwing consistently demonstrated a superior engineering performance, ultimately manifesting as maintenance of sufficient trawl SR with the least drag and therefore the lowest fuel intensity and rate (up to $2.26 \mathrm{~L} \mathrm{~h}^{-1}$ or $0.96 \mathrm{~L} \mathrm{ha}^{-1}$ lower, for double rig in the tested fishery). This result can be attributed to the two key aspects of the batwing's design:

295 (i) a baseplate aligned with the tow direction, which eliminated the shearing force on the bottom; and (ii) the hinged, hydrodynamic wing with a low AOA $\left(20^{\circ}\right)$, which reduced hydrodynamic drag (Sterling and Eayrs, 2010).

The inherent, consistent engineering benefits of the batwing are quite important, given that fuel can represent a large proportion (up to 30\%) of a trawler's operating costs (e.g. Thomas et al., 2010).

300 Any reduction in the overall trawl system drag will help to alleviate some of the fuel used during trawling; of which conventional otter boards typically represent anywhere from $30 \%$ in single rig configurations (Sterling and Eayrs, 2010) to the 56\% estimated here in experiment 3 (by comparing with data from experiment 2). Based on our data for the studied fishery, replacing any of the conventional otter-board pairs with the batwing would reduce fuel while trawling by between 16 and $22 \%$, which would equate to between $\sim$ \$ $2-3 \mathrm{~K}$ per fishing season. 
While there are numerous conventional otter-board designs, often incorporating complex foil and camber arrangements, which might similarly reduce hydrodynamic drag and improve efficiency, many fishers still use basic designs like the flat-rectangular (Patterson and Watts, 1985; Sterling et al., 2000). The popularity of the flat-rectangular otter board among local fishers is supported by the results from experiment 1 , with it having the least drag (by $\sim 5 \%$ ) of the conventional designs. Until recently, in many fisheries, the flat-rectangular otter board was among the most common designs operated (e.g. nearly 100\% usage in Australian prawn fisheries until the mid-1980s; Sterling and Eayrs, 2010); reflecting a combination of its simple, easily constructed and maintained design, and comparative efficiency to many contemporary otter boards when operated at $30-40^{\circ}$ AOA (e.g.

\section{Patterson and Watts, 1985; Seafish et al., 1993).}

While it is imperative that otter boards are appropriately rigged to maximise hydrodynamic performance (Sterling and Eayrs, 2010), their overall length is also important in terms of habitat impacts. For example, the cambered otter boards tested in experiment 1 had high substrate contact ( $62 \%$ of their length at the average $\left.38.62^{\circ} \mathrm{AOA}\right)$. The batwing offers a real solution to minimising

320 habitat impacts by having its main substrate contact (the sled) aligned in the direction of towing. Specifically, a conventional otter board $1.12 \mathrm{~m}$ long (the same as the batwing) operating at a typical AOA of $35-40^{\circ}$ will have $\sim 0.64-0.72 \mathrm{~m}$ of lateral contact compared to the $\sim 0.1 \mathrm{~m}$ wide baseplate (assuming minimal habitat disturbance of the 'flap') for the batwing. Using an otter board with a fixed (or low) AOA would also reduce system contact, but as demonstrated in experiment 1 , a 325 combination of AOA and otter-board length needs to be considered, because a long otter board at a shallow AOA could still contact more of the sea bed than a short design at a more acute AOA.

While reducing total system contact via otter-board configurations may help to mitigate habitat impacts, a concomitant effect could be reduced catches of penaeids (Broadhurst et al., 2012). The cambered otter boards currently are the preferred design in the Clarence River fishery-primarily

330 because they are perceived to catch more school prawns (supported by the results here) than other contemporary designs, which may in part result from their substantial ground contact. However, it is also possible that their large projected surface area (in the direction of the tow) is important. Specifically, this design had more projected area $\left(\sim 18-95 \%\right.$ or $\sim 0.07-0.24 \mathrm{~m}^{2}$ after adjusting for AOA) than the other otter-board designs. Even a small increase in projected area may have directed 335 more school prawns towards the trawl mouth. Such effects might also explain why, despite the lower substrate contact, the batwing maintained catches of school prawns in experiment 2. Specifically, the large sail and flap might have deflected some individuals close to the substratum into the trawls.

While the cambered otter boards improved school prawn catches, this was somewhat offset by their lower fuel efficiency than the flat-rectangular design. Such a result supports the concept that before implementing new otter-board designs (or other modifications), an holistic approach is necessary that allows profit margins to be maintained while increasing ecological efficiency. A comprehensive set of experiments (e.g. testing with a variety of trawl designs in different fisheries) is required; otherwise fishers are unlikely to commit to the continued use of new designs over the long term (Jennings and Revill, 2007).

345 It is also clear that introducing any technical modification requires careful adjustment and refinement across a broad range of conditions as possible prior to use. For example, in experiment 1 , the batwing was associated with significantly lower catches of school prawns than the conventional otter-board designs. We attributed this result to the more dynamic net attachment points-movable wire cables instead of fixed points on conventional designs-which may have permitted the trawl 350 wing to operate slightly higher in the water column, allowing sustained lateral opening of the meshes down the sides of the trawl-thus increasing escape opportunities. Using the batwing and flatrectangular boards with the smaller $(32 \mathrm{~mm})$ meshed trawls in experiment 2 negated these issues and resulted in catches not being significant different for the two otter board types. The importance of electronic monitoring equipment (e.g. Notus sensors and fuel meters) was reinforced by observing that changing to the smaller mesh trawl did not affect the relative differences in performance (e.g. wing-end spread, drag and fuel rates) between experiments.

The results from this study suggest that the batwing otter board has good potential for reducing fuel consumption while maintaining the catching performances of the assessed penaeid trawls. Using otter boards with minimal substrate contact (such as the batwing) will also potentially reduce damage 360 to trawled areas (van Marlen et al., 2010). While creating the definitive otter board may ultimately be 
difficult to achieve, we believe that to make significant improvements to overall trawl efficiency it may be more conducive to focus further research on an otter-board design that has already attained satisfactory engineering performance (e.g. the batwing) and work on improving its catching performance. The pair of batwings tested here would cost $\sim \$ \mathrm{~A} 3 \mathrm{~K}$ which is comparable to purchasing a pair of flat-rectangular otter boards and $\sim$ A $2 \mathrm{~K}$ less than the cambered otter boards. Batwing maintenance is equivalent to other otter boards, which combined with their superior fuel efficiency, should facilitate quicker investment returns (i.e. within one season, depending on which otter-board design they are replacing).

Alternatively, it might be advantageous to investigate the possibility of modifying existing designs-perhaps to incorporate the key mechanisms of designs such as the batwing to improve engineering and/or catching performances. While not specifically tested, based on our results, an otter board with superior engineering performance will also likely have a lower AOA, which has concomitant potential for reducing habitat impacts (Sterling and Eayrs, 2008; van Marlen et al., 2010).

\section{Acknowledgements}

This study was funded by the New South Wales (NSW) Department of Primary Industries and the Australian Fisheries Research and Development Corporation (FRDC; Grant no. 2011/010). Funding for developing and implementing the batwing otter board was provided by the World Wildlife Fund PA 01, PA 17; Enviro fund 62463; FRDC 2004/060, 2008/079. Thanks are extended to the (NSW) Professional Fisher's Association, Greg Skilleter, Steve Everson, Don Johnson, Jen Marshall, Chris Barnes, Mitch Burns, Nick Sarapuk, and especially Craig Brand.

\section{References}

385 Benjamini, Y., Yekutieli, D., 2001. The control of the false discovery rate in multiple testing under dependency. Ann. Statist. 29, 1165-1188.

Broadhurst, M.K., Sterling, D.J., and Cullis, B.R., 2012. Effects of otter boards on catches of an Australian penaeid. Fish. Res. 131-133, 67-75. performances of paired penaeid-trawling systems. Fish. Res. 143, 143-152.

Broadhurst, M.K., Sterling, D.J., Millar, R.B., 2013b. Progressing more environmentally benign penaeid-trawling systems by comparing Australian single- and multi-configurations. Fish. Res. $146,7-17$.

Caddy, J.F., 1973. Underwater observations on tracks of dredges and trawls and some effects of dredging on a scallop ground. J. Fish. Res. Board Can. 30, 173-180.

Gillett, R., 2008. Global study of shrimp fisheries. FAO Fisheries Technical Paper. No. 475. Food and Agriculture Organization of the United Nations, Rome, Italy, $331 \mathrm{pp}$.

Jennings S., Revill, A.S., 2007. The role of gear technologists in supporting and ecosystem approach to fisheries. ICES J. Mar.Sci. 64, 1525-1534.

400 Kaiser, M.J., Collie, J.S., Hall, S.J., Jennings, S., Poiner, I.R., 2002. Modification of marine habitats by trawling activities: prognosis and solutions. Fish Fish. 3, 114-136.

Kelleher, K., 2005. Discards in the world's marine fisheries. An update. FAO Fisheries Technical Paper 470, Food and Agriculture Organization of the United Nations, Rome, Italy, $131 \mathrm{pp}$.

McHugh, M.J., Broadhurst, M.K., Sterling, D.J., Millar, R.B., 2014. Comparing and modifying penaeid beam- and otter-trawls to improve ecological efficiencies. Fish. Manag. Ecol. 21, 299-311.

Patterson, R.N., Watts, K.C., 1985. The otter board as a low aspect ratio at high angle of attack; some theoretical aspects. Fish. Res. 3, 351-372.

Patterson, R.N., Watts, K.C., 1986. The otter board as a low-aspect-ratio wing at high angles of attack; an experimental study. Fish. Res. 4, 111-130.

Prado, J., 1990. Fisherman's Workbook. Food and Agriculture Organization of the United Nations, Fishing News Books, Oxford, 179 pp.

Rice, J.A., 2006. Mathematical Statistics and Data Analysis (third edition). Duxbury press. Belmont, CA, USA. 685 pp. 
Seafish, IFREMER, DIFTA, 1993. Otterboard performance and behaviour. Research project funded by Committee E.C. within the frame of the EEC research programme in the fisheries sector (FAR) Contract TE 1214. http://www.seafish.org/media/.../Otterboard_Performance_and_Behaviour.pdf

Sterling, D., 2000. The physical performance of prawn trawling otter boards and low opening systems. AME CRC Report, Project 1.4.4. Sterling Trawl Gear Services, Brisbane, 204 pp. http://trove.nla.gov.au/version/40532877

Sterling, D., Eayrs, S., 2008. An investigation of two methods to reduce the benthic impact of prawn trawling. Project 2004/060 Final Report. Canberra, Australia : Fisheries Research and Development Corporation, 96 pp.

425 http://frdc.com.au/research/Final_Reports/2004-060-DLD.PDF

Sterling, D., Eayrs, S., 2010. Trawl-gear innovations to improve the efficiency of Australian prawn trawling. First International Symposium on Fishing Vessel Energy Efficiency E-Fishing, Vigo, Spain, 5 pp.

Suuronen, P., Chopin, F., Glass, C., Løkkeborg, S., Matsushita, Y., Queirolo, D., Rihan, D., 2012. Low impact and fuel efficient fishing: looking beyond the horizon. Fish. Res. 119, 135-146.

Thomas, G., O'Doherty, D., Sterling, D., Chin, C., 2010. Energy audit of fishing vessels. Proc. IME M J. Eng. Marit. Environ. 224, 87-101.

van Marlen, B., Piet, G.J., Hoefnagel, E., Taal, K., Revill, A.S., Wade, O., O’Neill, F.G., Vincent, B., Vold, A., Rihan, D., Polet, H., Stouten, H., Depestele, J., Eigaard, O.R., Dolmer, P., Frandsen, R.P., Zacha-riassen, K., Madsen, N., Innes, J., Ivanovic, A., Neilson, R.D., Sala, A., Lucchetti, A., De Carlo, F., Canduci, G., Robinson, L.A., Alexander, M., 2010. Development of fishing Gears with Reduced Effects on the Environment (DEGREE). Final Publishable Activity Report - EU Contract SSP8-CT-2004-022576, 239 pp.

Wakeford, J., 2010. Development and implementation of an energy audit process for Australian fishing vessels. FRDC Final Report, Project No. 2006/229, 178.pp.

Wardle, C.S., 1989. Understanding fish behaviour can lead to more selective fishing gears. In: C. M. Campbell (ed) Proceedings of the World Symposium on Fishing Gear and Fishing Vessel Design. November 1988. Marine Institute, St Johns, NF, Canada pp. 12-18 
Table 1. Scientific and common names and numbers of organisms caught during experiments (exp) 1 and 2 . -, not present in catches.

Family

Scientific name

Common name

Total numbers

Crustaceans

Palaemonidae

Penaeidae

485

Macrobrachium novaehollandiae Metapenaeus macleayi

Penaeus monodon

Freshwater prawn

School prawn

Tiger prawn

3

182,568

164,424

Teleosts

Ambassidae

Ambassis jacksoniensis

Port Jackson glassfish 3

Ambassis marianus

Anguillidae

Ariidae

Anguilla reinhardtii

Arius graeffei

Apogonidae

Carangidae

Clupeidae

495

Engraulidae

Gerreidae

Megalopidae

Monodactylidae

500

Mugilidae

Paralichthyidae

Platycephalidae

Plotosidae

Pomatomidae

505

Scatophagidae

Sciaenidae

Soleidae

Sparidae

Siphamia roseigaster

Pseudocaranx dentex

Herklotsichthys castelnaui

Hyperlophus vittatus

Engraulis australis

Gerres subfasciatus

Megalops cyprinoides

Monodactylus argenteus

Liza argentea

Pseudorhombus arsius

Platycephalus fuscus

Euristhmus lepturus

Pomatomus saltatrix

Selenotoca multifasciata

Argyrosomus japonicus

Synclidopus macleayanus

Acanthopagrus australis

Rhabdosargus sarba

Tetrarogidae

Notesthes robusta
Ramsey's perchlet 11

Long-finned eel 8

Forktail catfish $\quad 728$

Silver trevally $\quad-\quad-1$

Southern herring $\quad 275 \quad 138$

$\begin{array}{lll}\text { Whitebait } & 7 & 4\end{array}$

Australian anchovy $\quad-\quad 2$

$\begin{array}{lll}\text { Silver biddy } & 3 & 27\end{array}$

Oxeye herring $\quad-\quad 3$

Diamond fish $\quad 6 \quad 40$

Flat-tail mullet $\quad-\quad$ 1

$\begin{array}{lll}\text { Largetooth flounder } \quad- & 4\end{array}$

Dusky flathead $\quad 1 \quad 2$

Longtail catfish $\quad 4 \quad 3$

$\begin{array}{lll}\text { Tailor } & 12 & 11\end{array}$

Old maid $\quad 5 \quad 4$

Mulloway $\quad 184 \quad 63$

Narrow banded sole $\quad 81 \quad 13$

$\begin{array}{lll}\text { Yellowfin bream } & 119 & 750\end{array}$

Tarwhine $\quad-\quad 1$

$\begin{array}{lll}\text { Bullrout } & 33 & 76\end{array}$ 
Table 2. Summaries of likelihood ratio test (LRT) statistics from linear mixed models assessing the importance of the fixed effect of otter-board pairs in experiments (exp) 1 (flat-rectangular, kilfoil, cambered and batwing attached to identical 41-mm mesh trawls), 2 (flat-rectangular and batwing attached to identical 32-mm mesh trawls) and 3 (flat-rectangular and batwing with no trawls) in explaining variability among key technical and, where relevant, biological responses. Numbers and weights were analysed as log-transformed data, after being standardised to per ha trawled calculated using the foot-rope contact (average wing-end spread $\times$ distance trawled) and, additionally where these were significant for the school prawns, the total-system contact ((i.e. wing-end spread + span of otter-board contact) $\times$ the distance trawled). - , not present in sufficient numbers. NA, not applicable

520 for analyses; $\uparrow$, no LRT available because the batwing otter board maintained a constant $20^{\circ}$ angle of attack (AOA). Owing to a significant interaction with SOG, no main effect of otter board was presented for drag in experiments 2 and 3 (see Table 3).

Technical variables

$\operatorname{Exp} 1$

LRT

Wing-end (exp 1 and 2) or otter board (exp 3) spread

$\operatorname{Exp} 2$

$\operatorname{Exp} 3$

Distance trawled

0.87

0.04

$9.27 * *$

Otter-board AOA

$33.46^{* * *}$

1.03

1.07

Total bottom contact

$41.27 * * *$

$\dagger * * *$

$\dagger * * *$

Drag

9.64*

$7.81^{* * *}$

NA

530

Drag

Biological variables

Wt of school prawns ha ${ }^{-1}$ of footrope contact

$18.89 * * *$

0.76

NA

Wt of school prawns ha ${ }^{-1}$ of total-system contact

$9.13 *$

NA

NA

535

No. of school prawns ha ${ }^{-1}$ of footrope contact

$12.78^{* *}$

1.13

NA

No. of school prawns ha ${ }^{-1}$ of total-system contact

6.02

NA

NA

CL of school prawns

$8.19 *$

2.54

NA

Wt of total bycatch ha ${ }^{-1}$ of footrope contact

0.72

0.10

NA

No. of total bycatch ha ${ }^{-1}$ of footrope contact

1.00

0.22

NA

540

No. of yellowfin bream ha ${ }^{-1}$ of footrope contact

$-$

2.87

NA

No. of forktail catfish ha ${ }^{-1}$ of footrope contact

3.36

0.41

NA

No. of southern herring ha ${ }^{-1}$ of footrope contact

4.47

0.42

NA

No. of mulloway ha ${ }^{-1}$ of footrope contact

0.69

NA

$* p<0.05$

$* * p<0.01$

$* * * p<0.001$ 
Table 3. Summary of predicted mean $\pm \mathrm{SE}$ wing-end spreads or footrope contact $(\mathrm{m})$, otter-board angles of attack (AOA), otter-board projected area ( $\left.\mathrm{m}^{2}\right)$, total bottom (foot rope + otter-board base-plate linear span) contact (m), drags (kgf) and subsequent estimated fuel rates and intensities for four pairs of otter boards (flat-rectangular, kilfoil, cambered and batwing otter boards) attached to identical 41-mm mesh trawls in experiment 1 and two pairs of otter boards (flat-rectangular and batwing) attached to identical 32-mm mesh trawls in experiment 2, and spread, AOA and drags for the pairs of the flat-rectangular and batwing otter boards tested without trawls in experiment 3 . Mean predicted drags were derived with a centred value of speed over the ground and with zero current. The predicted areas (of individual otter boards) were derived from the percentage of overall surface area when correcting for AOA. Dissimilar superscript letters within experiments indicate significant differences detected in false-discovery-rate pairwise comparisons (experiment 1$)$ or linear mixed models (experiments 2 and 3$)(P<0.05)$. - , Not applicable.

Experiment 1- four otter-board pairs with 41-mm mesh trawls

Wing-end spread or foot rope contact (m)

Otter-board AOA $\left(^{\circ}\right)$

Otter-board projected area $\left(\mathrm{m}^{2}\right)$

Total bottom contact $(\mathrm{m})$

Drag (kgf)

Fuel rate $\left(\mathrm{L} \mathrm{h}^{-1}\right)$

Fuel intensity $\left(\mathrm{L} \mathrm{ha}^{-1}\right)$

\begin{tabular}{llll} 
& \multicolumn{2}{c}{ Otter board pairs } & \\
Flat-rectangular & Kilfoil & Cambered & Batwing \\
& & & \\
$5.08(0.06)^{\mathrm{A}}$ & $5.17(0.06)^{\mathrm{A}}$ & $5.13(0.06)^{\mathrm{A}}$ & $5.10(0.06)^{\mathrm{A}}$ \\
$32.83(0.40)^{\mathrm{C}}$ & $30.58(0.40)^{\mathrm{B}}$ & $38.62(0.40)^{\mathrm{D}}$ & $20(0.00)^{\mathrm{A}}$ \\
0.41 & 0.29 & 0.48 & 0.25 \\
$6.58(0.07)^{\mathrm{B}}$ & $6.44(0.07)^{\mathrm{B}}$ & $6.47(0.07)^{\mathrm{B}}$ & $5.30(0.07)^{\mathrm{A}}$ \\
$251.57(2.45)^{\mathrm{B}}$ & $264.94(3.18)^{\mathrm{C}}$ & $264.46(2.46)^{\mathrm{C}}$ & $216.33(3.18)^{\mathrm{A}}$ \\
5.82 & 6.13 & 6.12 & 5.00 \\
2.57 & 2.66 & 2.68 & 2.20
\end{tabular}

Experiment 2- two otter-board pairs with 32-mm mesh trawls

Wing-end spread $(\mathrm{m})$

Otter-board AOA $\left(^{\circ}\right)$

Otter-board projected area $\left(\mathrm{m}^{2}\right)$

Total bottom contact (m)

Drag (kgf)

Fuel rate $\left(\mathrm{L} \mathrm{h}^{-1}\right)$

Fuel intensity $\left(\mathrm{L} \mathrm{ha}^{-1}\right)$

$5.17(0.12)^{\mathrm{A}}$

$33.71(0.98)^{\mathrm{B}}$

0.42

$6.73(0.15)^{\mathrm{B}}$

$268.14(2.08)^{\mathrm{B}}$

6.21

2.33

$2.59(0.10)^{\mathrm{A}}$

$32.59(2.13)^{\mathrm{B}}$

$158.65(3.79)^{\mathrm{B}}$
$5.12(0.12)^{\mathrm{A}}$

$20(00)^{\mathrm{A}}$

0.25

$5.32(0.15)^{\mathrm{A}}$

$227.93(2.01)^{\mathrm{A}}$

5.28

2.00

$2.92(0.10)^{\mathrm{B}}$

$20(00)^{\mathrm{A}}$

$116.74(3.77)^{\mathrm{A}}$ 
Table 4. Differences in predicted mean catch variables per ha trawled of foot-rope contact (average wing-end spread $\times$ distance trawled) between identical 32-mm mesh trawls spread with pairs of flatrectangular and batwing otter boards.

580

Variables

Wt of school prawns ha ${ }^{-1}$ trawled

No. of school prawns ha ${ }^{-1}$ trawled

Wt of total bycatch ha ${ }^{-1}$ trawled

585
Batwing

5.43

2044.76

0.46

16.00

9.61

0.86

1.74

43
No. of yellowfin bream ha ${ }^{-1}$ trawled

No. of forktail catfish ha ${ }^{-1}$ trawled

No. of southern herring $\mathrm{ha}^{-1}$ trawled
Fla-rectangular

5.61

2209.02

0.48

17.57

13.37

0.76

1.43 


\section{Captions to Figures}

590 Fig. 1. Plans of the 41- and 32-mm trawls used in the study. N, normal; T, transversals; B, Bars; and $\varnothing$, diameter (information in bold is specific to the 32-mm trawl).

Fig. 2. Three-dimensional representation of a) flat-rectangular, b) kilfoil, c) cambered and d) batwing otter boards. The $0.67 \mathrm{~m}$ represents sweep-line attachment points.

Fig. 3. Front and top views of the (a) flat-rectangular and (b) batwing otter boards rigged without a trawl in experiment 3.

Fig. 4. Differences in predicted mean catches per ha trawled of foot-rope contact (grey histograms) and, where relevant, total-system contact (black histograms) between identical 41-mm mesh trawls spread with pairs of flat-rectangular, kilfoil, cambered and batwing otter boards for the (a) weights and (b) numbers of school prawns (Metapenaeus macleayi), (c) weights and (d) numbers of bycatch and numbers of (e) forktail catfish, Arius graeffei, (f) southern herring, Herklotsichthys castelnaui and (g) mulloway, Argyrosomus japonicus. Dissimilar letters and numbers above the 605 histograms indicate significant differences detected in false-discovery-rate pairwise comparisons $(p<0.05)$. 

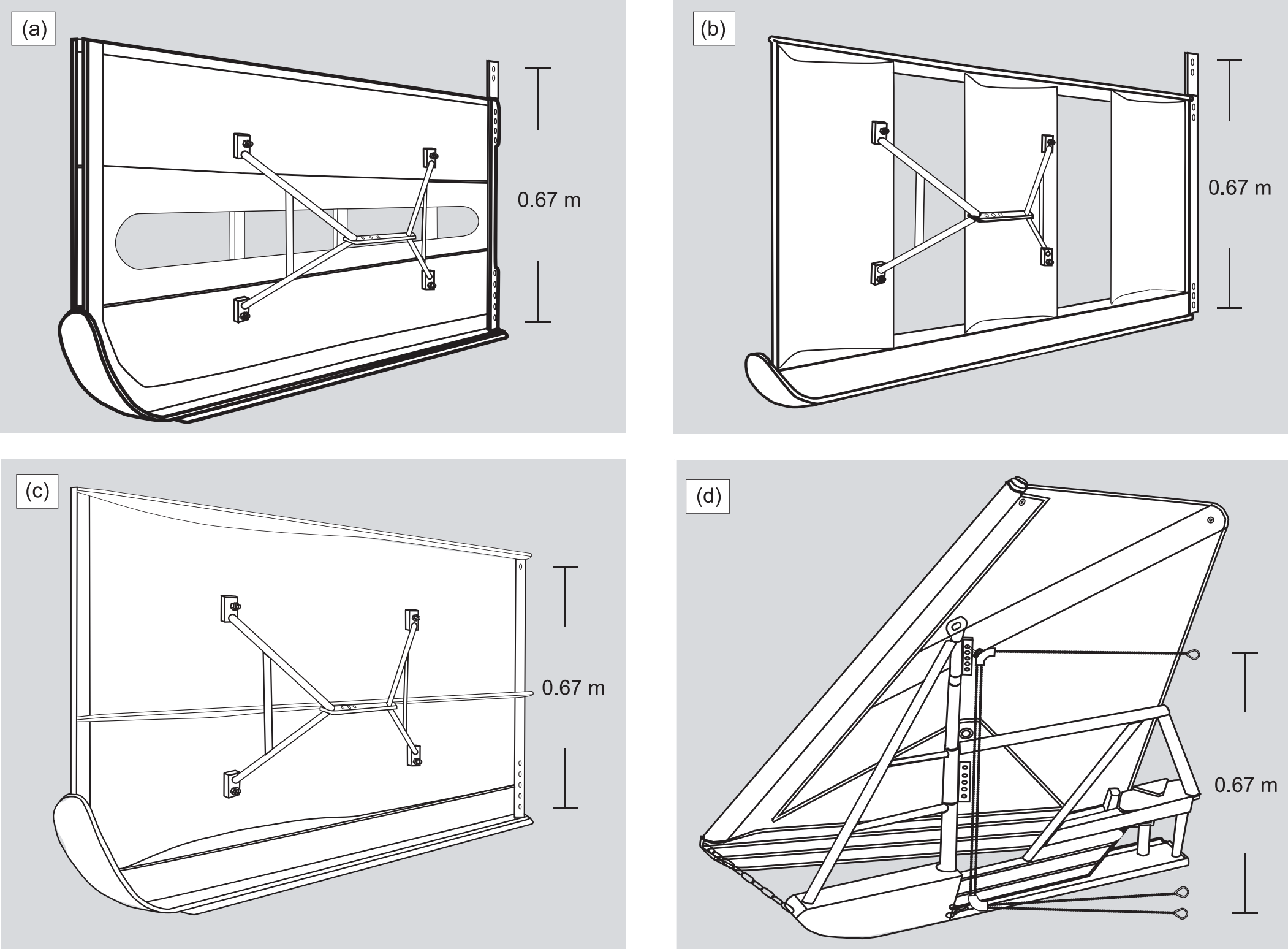

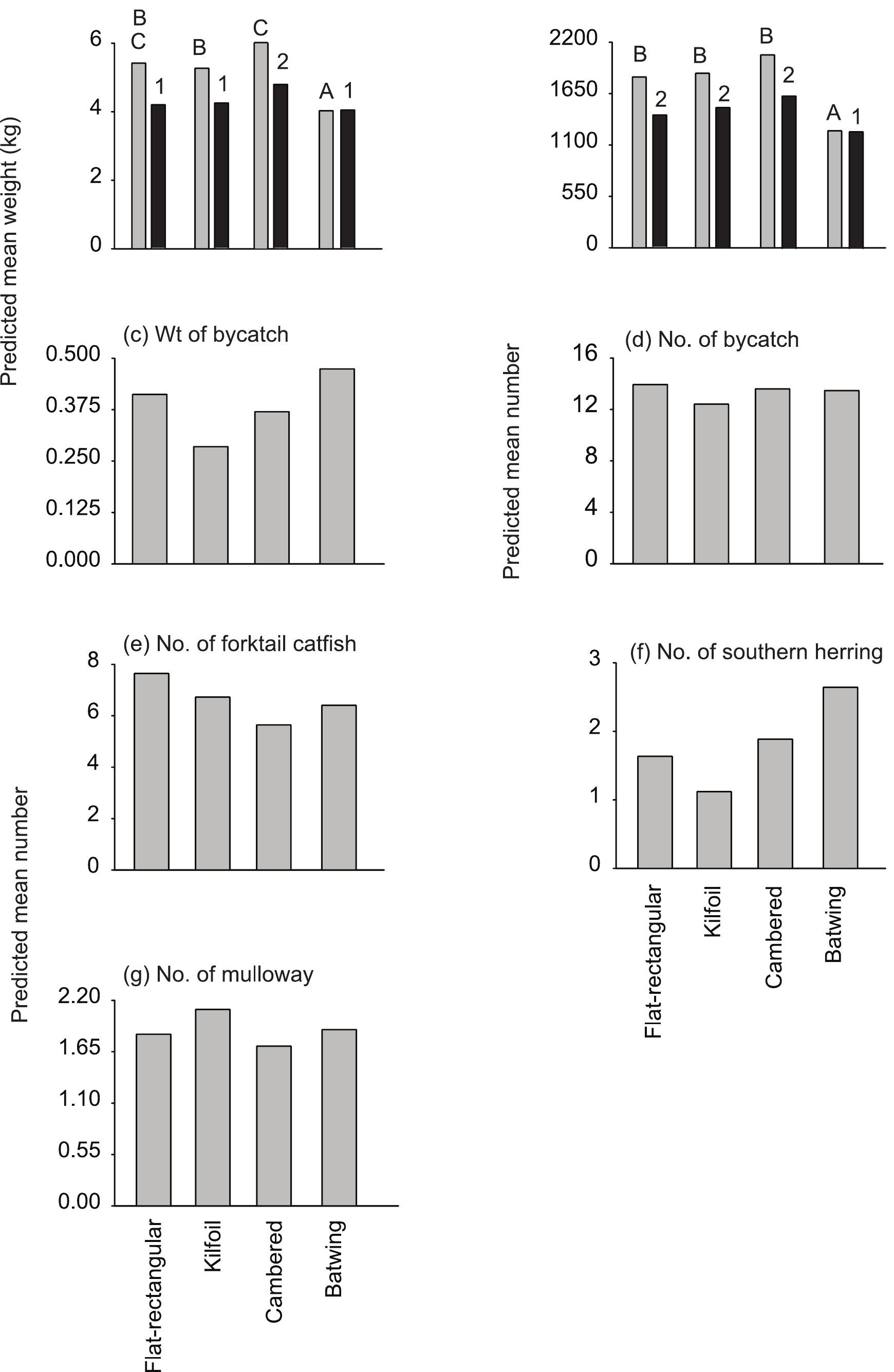